\title{
The Inhibition of Bolt Connection Slip and Experimental Research in The Power Transmission Tower
}

\author{
Mingming Li \\ School of Mechanical Engineering,North China Electric Power University, Baoding 071000, China.
}

969257623@qq.com,

Keywords: Transmission tower, Connection slip,Bolted connection, oblong bolted holes.

\begin{abstract}
In transmission towers,ordinary galvanized bolts are widely used to connect angles,the connection properties determine the slippage at the nodes.The node connections are assumed to be rigid or hinge in traditional analysis and design of transmission tower, which make the status different from the real towers,A large number of experiments of the real towers suggested that the results of the calculation have a great difference with the experiments.In order to reduce the effect of bolted slip,the study put forward using an oblong bolt hole and arrangement of the hole .Imitating the tension process of the bolted connections by ANSYS simulation and present the influence of the connection slippage when the included angle between length direction oblongs and axis direction of angle changing and the pre-tightening force is different.Through the study we found that:the angle of the length direction of oblong bolted hole and the axis of the angle is larger,the pre-tightening force of the bolts is stronger,the bolted connection slip is smaller.
\end{abstract}

\section{Introduction}

In the early 1960s, based on the true type tower experiments found the slip phenomenon existing in the transmission tower,Peterson pointed out that in the measurement to the tower of the biggest deformation,caused by node slip deformation accounts for nearly half of the maximum deformation[1].Marjerrison also pointed out that in some experiments of the tower,measure the displacement value nearly three times the space truss method to calculate the result and a big part of the reason for the connection of slip[2]. N.Ungkurapinan also point out this phenomenon[3].Wenqiang Zhang detailed analysis of the slip shearing process of ordinary bolt connecting[4]. Because of bolted connection slip exists,but at this stage tower structure internal force calculation think that the nodes just answer or pin,the design to calculate the internal force and true type tower vary widely.This study presents a new type of bolt holes,oblong bolted holes,control slipping of the bolted connection and reduce the influence of bolt connection slip on transmission tower.

\section{The Slip of Bolt connection}

As a result of the existence of machining error and setting error,there is gap between bolt holes and bolt rod to ensure the installation.Outside a horizontal load on the connecting plate,when the load is greater than the nut and connection plate's friction,bolt connection will produce a slip.
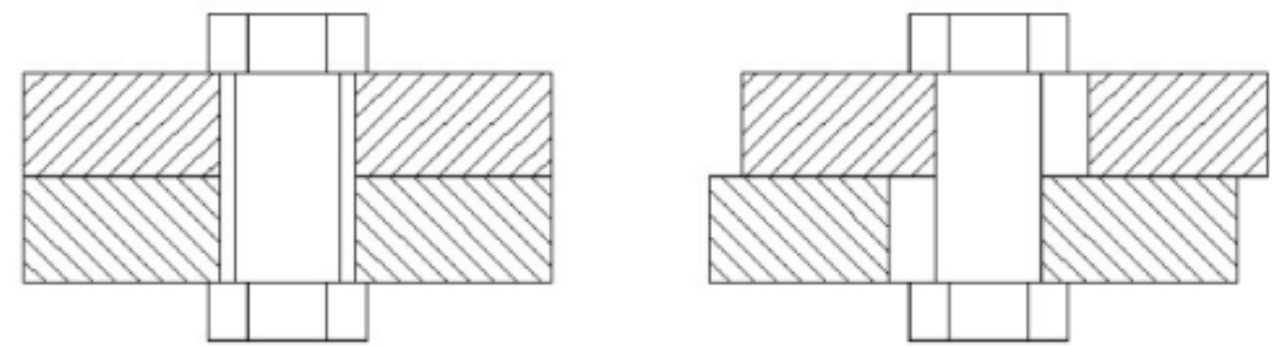

Fig. 1 The diagram of the sliding of bolt connection 


\section{The control method of the Slip of Bolt connection}

The obvious, if the diameter of the bolt hole size the same as the bolt,so between bolt and bolt hole will not have any gaps,will not slip,but in the process of processing and installation,once a slight deviation will not be able to install,it is not allowed.If the bolt holes are oblong bolt hole,bolt connection will not be able to produce the relative sliding between angle,so we can guarantee the process installation error and control the slip at the same time.

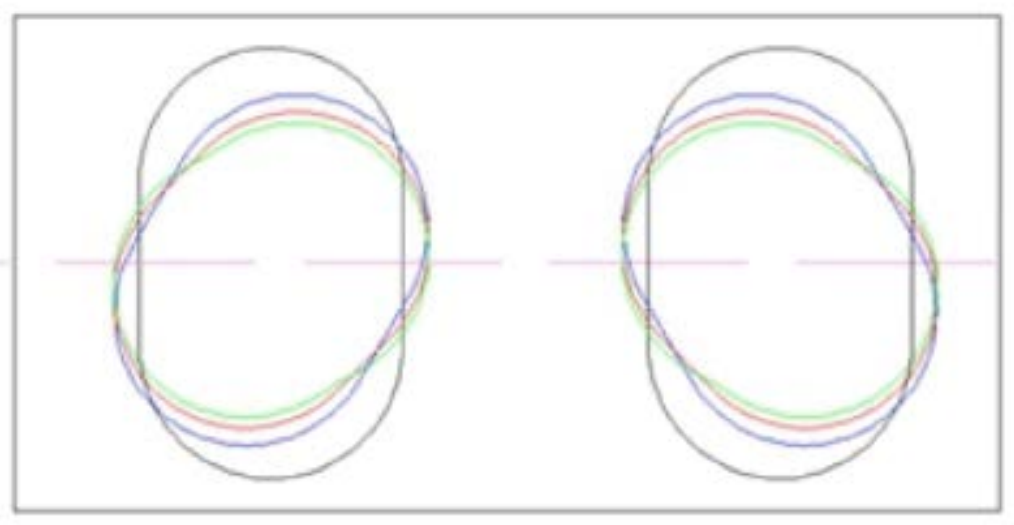

Fig. 2 The oblong bolt holes of different angles

The simulation analysis of the Slip of Bolt connection

The model parameter of circular bolt hole

\begin{tabular}{|c|c|c|c|c|}
\hline $\begin{array}{c}\text { The width of } \\
\text { connection plate }\end{array}$ & $\begin{array}{c}\text { The thickness of } \\
\text { connection plate }\end{array}$ & $\begin{array}{c}\text { The diameter of } \\
\text { the bolt hole }\end{array}$ & $\begin{array}{c}\text { The diameter of } \\
\text { the bolt rod }\end{array}$ & $\begin{array}{c}\text { The length of } \\
\text { the bolt rod }\end{array}$ \\
\hline $56 \mathrm{~mm}$ & $5 \mathrm{~mm}$ & $17.5 \mathrm{~mm}$ & $16 \mathrm{~mm}$ & $9.794 \mathrm{~mm}$ \\
\hline
\end{tabular}

\begin{tabular}{|c|c|}
\hline $\begin{array}{c}\text { The diameter of } \\
\text { the nut }\end{array}$ & $\begin{array}{c}\text { The thickness of } \\
\text { the nut }\end{array}$ \\
\hline $24 \mathrm{~mm}$ & $10 \mathrm{~mm}$ \\
\hline
\end{tabular}

External load-deformation curve of the circular hole and the stress nephogram was same as the predecessor's research results.

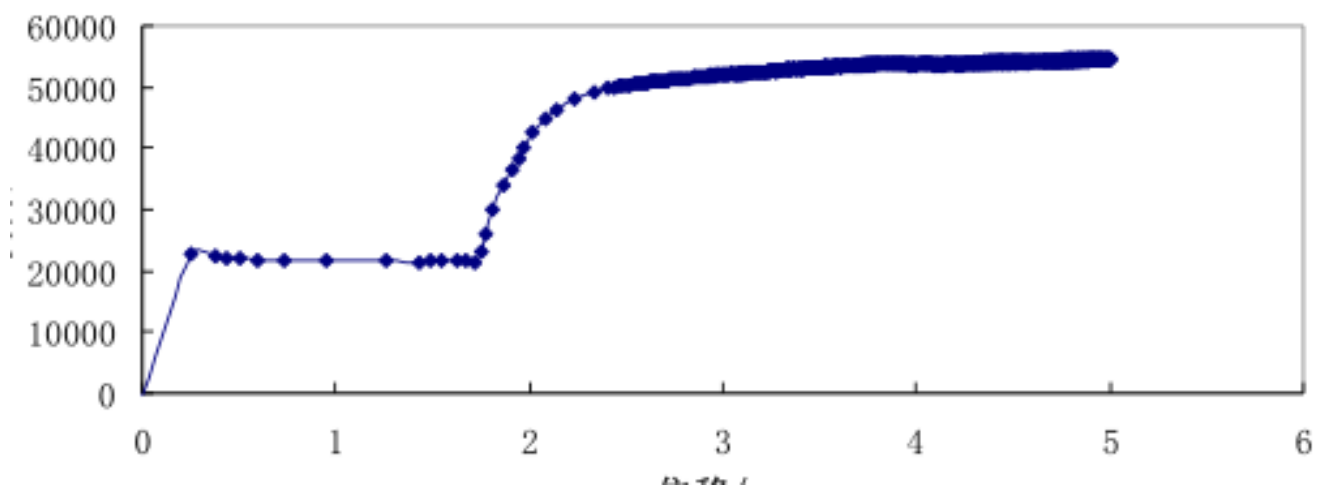

Fig. 3 External load-deformation curve of the circular hole 

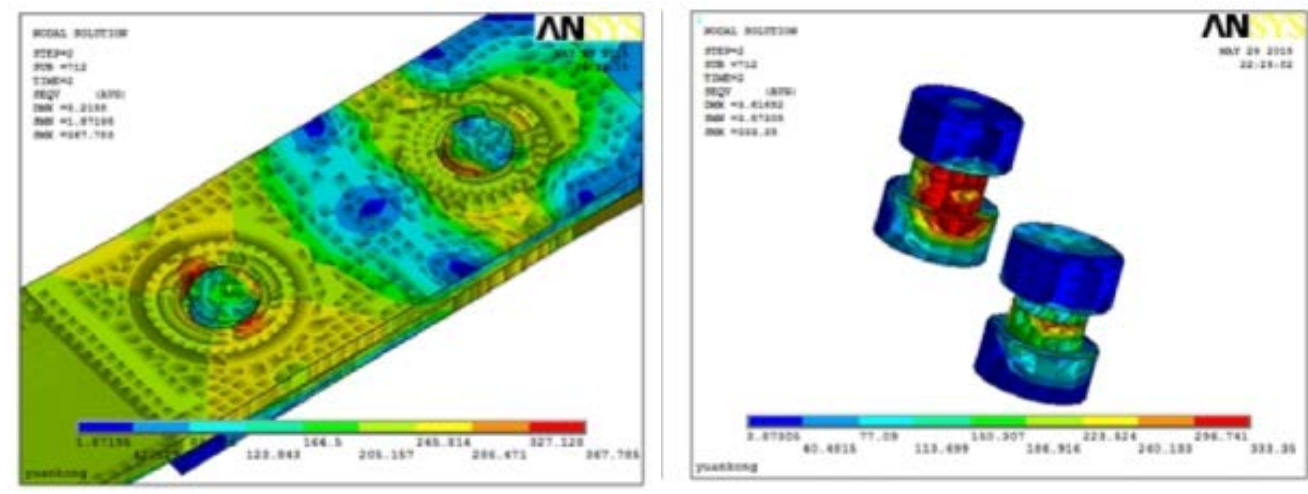

Fig. 4 The stress nephogram of the circular hole

The model parameter of oblong bolted holes

\begin{tabular}{|c|c|c|c|c|}
\hline $\begin{array}{c}\text { The width of } \\
\text { connection plate }\end{array}$ & $\begin{array}{c}\text { The thickness of } \\
\text { connection plate }\end{array}$ & $\begin{array}{c}\text { The length of } \\
\text { oblong bolted } \\
\text { holes }\end{array}$ & $\begin{array}{c}\text { The diameter of } \\
\text { semicircle }\end{array}$ & $\begin{array}{c}\text { The length of } \\
\text { the bolt rod }\end{array}$ \\
\hline $56 \mathrm{~mm}$ & $5 \mathrm{~mm}$ & $3 \mathrm{~mm}$ & $16 \mathrm{~mm}$ & $9.794 \mathrm{~mm}$ \\
\hline
\end{tabular}

\begin{tabular}{|c|c|}
\hline $\begin{array}{c}\text { The diameter of } \\
\text { the nut }\end{array}$ & $\begin{array}{c}\text { The thickness of } \\
\text { the nut }\end{array}$ \\
\hline $24 \mathrm{~mm}$ & $10 \mathrm{~mm}$ \\
\hline
\end{tabular}

External load-deformation curve of oblong bolted holes and the stress nephogram

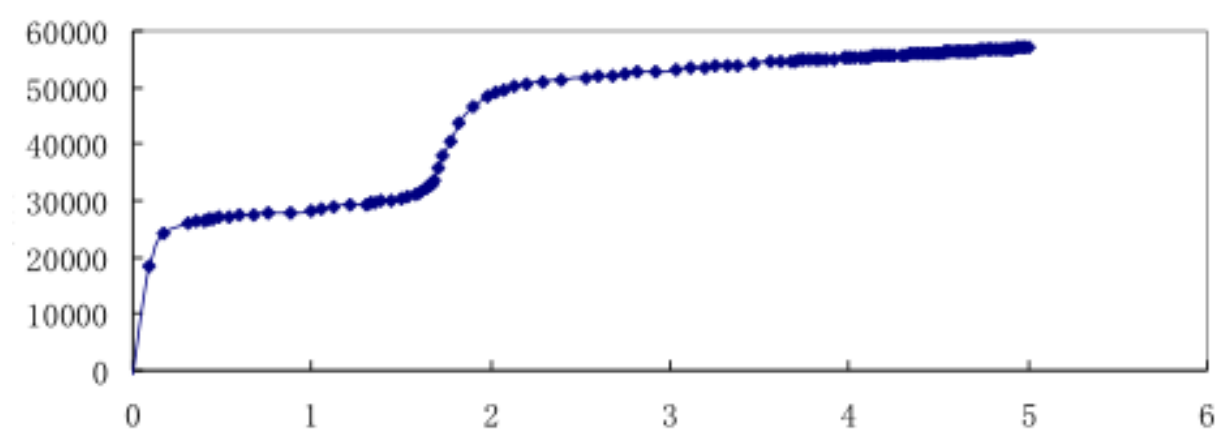

Fig. 5 External load-deformation curve of the oblong bolted holes

$$
\theta=60^{\circ}
$$
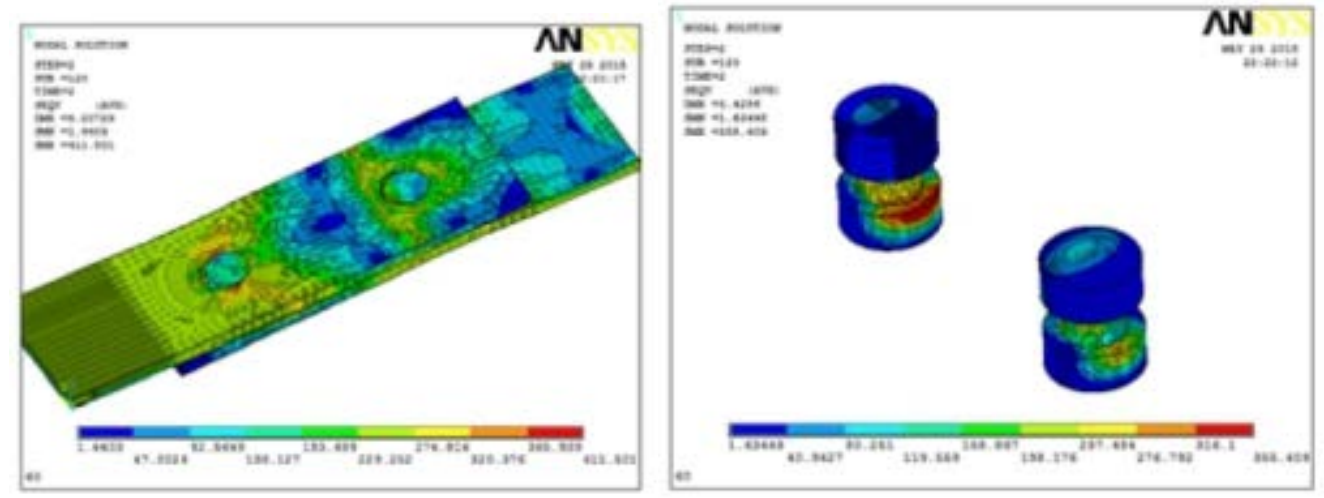

Fig. 6 The stress nephogram of the oblong bolted holes

Through the ANSYS simulation,we can get that this proposed method is effective and bolt connection has improved. 


\section{Different angles of bolt holes}

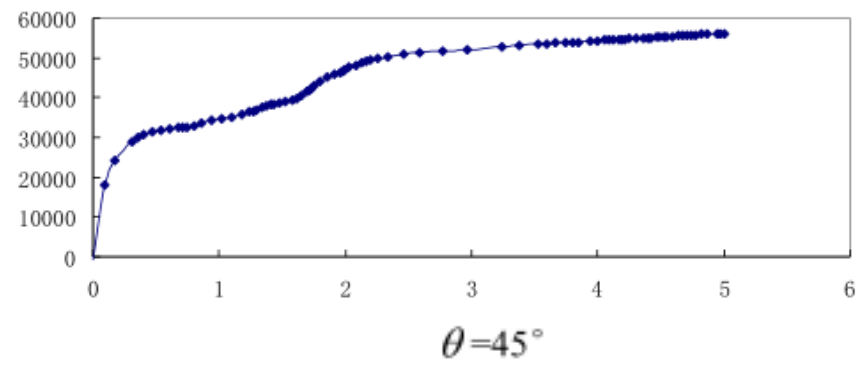

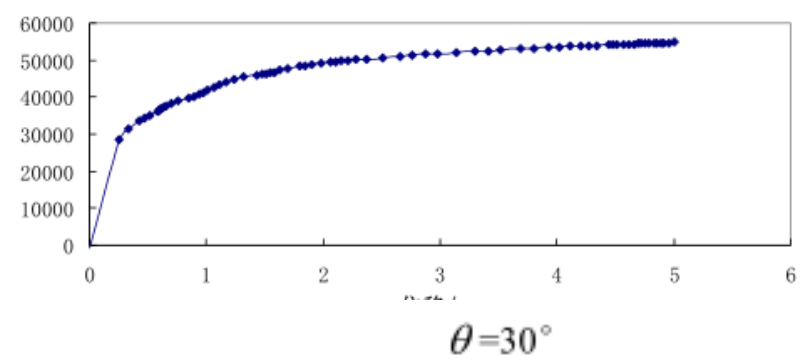

Fig. 7 External load-deformation curve of the oblong bolted holes Through the study we found that:the angle of the length direction of oblong bolted hole and the axis of the angle is larger,the bolted connection slip is smaller.

\section{Summary}

Imitating the tension process of the bolted connections by ANSYS simulation and present the influence of the connection slippage when the included angle between length direction oblongs and axis direction of angle changing and the pre-tightening force is different.Through the study we found that:the angle of the length direction of oblong bolted hole and the axis of the angle is larger,the pre-tightening force of the bolts is stronger,the bolted connection slip is smaller.

\section{Acknowledgments}

This work was financially supported by North China Electric Power University.

\section{References}

[1] Peterson,W O.Design of EHV steel tower transmission lines[J].Journal of the Structural Division,Proceedings of the American Society of Civil Engineers, 1962

[2] Marjerrison M M.Electric transmission tower design [J].Journal of the Structrual Division, Proceedings of the American Society of Civil Engineers, 1962

[3] N.Ungkurapinan. Joint slip in steel electric transmission tower[J].Engineering structure,2003

[4]Wenqiang Zhang.Detailed simulation of structure nodes and in the application of transmission tower structure analysis[D],Mechanical Engineering,North China Electric Power University,2011 